TITLE:

\title{
Effect of grain refinement on hydrogen embrittlement behaviors of high-Mn TWIP steel
}

$\operatorname{AUTHOR}(S):$

Bai, Y.; Momotani, Y.; Chen, M.C.; Shibata, A.; Tsuji, N.

\section{CITATION:}

Bai, Y.... [et al]. Effect of grain refinement on hydrogen embrittlement behaviors of highMn TWIP steel. Materials Science and Engineering: A 2016, 651: 935-944

\section{ISSUE DATE:}

2016-01

URL:

http://hdl.handle.net/2433/204076

\section{RIGHT:}

(c) 2015. This manuscript version is made available under the CC-BY-NC-ND 4.0 license

http://creativecommons.org/licenses/by-nc-nd/4.0/; The full-text file will be made open to the public on 1 January 2018 in accordance with publisher's 'Terms and Conditions for Self-Archiving'.; This is not the published version. Please cite only the published version.; この論文は出版社版でありません。引用の際には出版社版をご確認ご利用ください。 


\title{
Effect of grain refinement on hydrogen embrittlement behaviors of high-Mn TWIP steel
}

\author{
Y. Bai ${ }^{a^{*}}$, Y. Momotani ${ }^{a}$, M. C. Chen ${ }^{\text {a }}$, A. Shibata ${ }^{a, b}$, and N. Tsuji ${ }^{a, b}$ \\ ${ }^{a}$ Department of Materials Science and Engineering, Kyoto University, Yoshida-honmachi, \\ Sakyo-ku, Kyoto, 606-8501, Japan \\ ${ }^{\mathrm{b}}$ Elements Strategy Initiative for Structural Materials (ESISM), Kyoto University, \\ Yoshida-honmachi, Sakyo-ku, Kyoto, 606-8501, Japan
}

\begin{abstract}
Hydrogen embrittlement behaviors of a high-Mn TWIP (twinning induced plasticity) steel with various grain sizes from coarse grains to ultra-fine grains were studied by hydrogen pre-charging and subsequent slow stain rate tensile tests. The results of the tensile tests showed that the yield strength and tensile strength were not influenced by hydrogen-charging, whereas the total elongation reduced with hydrogen-charging in coarse-grained specimen but no change in the ultrafine-grained specimen. Fracture surfaces showed dimple patterns in all specimens. The present results suggested that the grain refinement suppressed hydrogen embrittlement in the high-Mn TWIP steel, even though the diffusible hydrogen content increased by grain refinement.
\end{abstract}

Keywords: Twinning induced plasticity (TWIP) steel; grain refinement; tensile property; hydrogen embrittlement; grain boundary

* Corresponding author, E-mail: yu.bai@tsujilab.mtl.kyoto-u.ac.jp 


\section{Introduction}

In the past decades, a new group of high manganese austenitic (face-centered cubic: FCC) steels showing both high strength and large ductility has been developed. They are called twinning induced plasticity (TWIP) steel [1]. These alloys have been drawing great attention from the researchers and industries because of the excellent mechanical properties. The superior mechanical properties are due to the deformation twinning during deformation, which is controlled by the stacking fault energy (SFE).

For austenitic steels, it is considered that martensitic transformation takes place when they have SFE lower than $20 \mathrm{~mJ} / \mathrm{m}^{2}$ [2]. In contrast, a higher SFE $(>50 \mathrm{~mJ} /$ $\mathrm{m}^{2}$ ) leads to only dislocation slip [3]. Between the range of $20-40 \mathrm{~mJ} / \mathrm{m}^{2}$, phase transformation is suppressed but deformation twinning is enhanced, which results in a large work hardening and good ductility (large uniform elongation) [4]. On the other hand, the SFE is mainly controlled by the chemical composition. The manganese content in TWIP steel is in the range of $15-30 \mathrm{wt} . \%$ [3]. The addition of aluminum increases the SFE while silicon decreases the SFE. The present research focused on a high-Mn steel with addition of both aluminum and silicon that undergoes deformation twinning and dislocation slip but no martensitic phase transformation.

Given that single-phase austenitic TWIP steels do not generally suffer from hydrogen embrittlement because of low diffusivity and high solubility of hydrogen in FCC structured materials compared with body-centered cubic (BCC) structured 
martensitic steels $[5,6,7,8]$. However, recently some researches have reported that various kinds of TWIP steels, Fe-Mn-C and Fe-Mn-C-Al, also show significant hydrogen embrittlement behaviors during tensile tests in hydrogen pre-charged or in-situ chemical charged situations [3, 9]. Factors affecting hydrogen embrittlement have been reported to be the diffusible hydrogen content [10], pre-strain [11] and material strength (or microstructure) [12]. The susceptibility of steels to hydrogen embrittlement generally increases with increasing the above mentioned factors.

There are many strengthening mechanisms for single-phase metals, such as grain size refinement, solid-solution alloying, and strain hardening [13]. Grain refinement is a way for strengthening metallic materials without changing its chemical composition. Saha et al. [14] succeeded in fabricating fully recrystallized ultrafine-grained microstructures with grain sizes much smaller than $1 \mu \mathrm{m}$ in a TWIP steel with chemical composition of Fe-31Mn-3Al-3Si (mass \%), through conventionally cold-rolling and subsequent annealing. The ultrafine-grained TWIP steel showed very high yield strength as well as good strain-hardening, without losing tensile ductility [14]. In general, hydrogen embrittlement susceptibility increases with increasing the strength [15]. Consequently, hydrogen embrittlement behavior might be one of the serious problems for practical use of fine-grained TWIP steels with high strength. However, there are few studies concerning the effect of grain size on the hydrogen embrittlement behaviors. In order to understand the influence of grain size on hydrogen embrittlement behaviors, an Fe-31Mn-3Al-3Si TWIP steel with various grain sizes (including sub-micron size) have been fabricated, and the 
changes in mechanical properties and fracture surface have been investigated by conducting slow strain rate tensile tests using hydrogen pre-charged specimens in the present work.

\section{Experimental procedure}

A 31Mn-3Al-3Si (mass \%) high-Mn single-phase austenitic TWIP steel was used in the present study. The chemical composition of this material is listed in Table 1. The SFE of this material is less than $40 \mathrm{~mJ} / \mathrm{m}^{2}$ according to a thermodynamic model [16]. As-received hot-rolled plate with a thickness of $12 \mathrm{~mm}$ was cold-rolled to a thickness of $1 \mathrm{~mm}$ with a total reduction of $92 \%$ (the equivalent strain $\varepsilon=2.87$ ). The multi-pass rolling process was conducted at room temperature under a lubricated condition, using a two-high rolling mill with rolls of $250 \mathrm{~mm}$ in diameter. In order to obtain fully recrystallized microstructures with various grain sizes, the cold-rolled sheet was annealed at temperatures of $650{ }^{\circ} \mathrm{C}$ or $800{ }^{\circ} \mathrm{C}$ for 0.3 $\mathrm{ks}$ in a salt bath, or $1000{ }^{\circ} \mathrm{C}$ for $1.8 \mathrm{ks}$ in a vacuum furnace, followed by water quenching.

The annealed specimens were mechanically polished using emery papers and diamond pastes, and then electrically polished in a solution of $\mathrm{HClO}_{4}+\mathrm{CH}_{3} \mathrm{COOH}$ with a ratio of $1: 9$ at $30 \mathrm{~V}$ for $30 \mathrm{~s}$ at room temperature. The microstructures of the annealed specimens were observed by a field emission scanning electron microscope (FE-SEM) attached with back scattered electron (BSE) and electron backscattering 
diffraction (EBSD) analyzer. All microstructural observations were carried out on the longitudinal sections from the transverse direction (TD) of the sheets.

The sheet type tensile test specimens with a gauge length of $10 \mathrm{~mm}$ and width of $5 \mathrm{~mm}$ were cut from the $1 \mathrm{~mm}$ thick annealed sheets using an electrical discharge machine. Since diffusion coefficient of hydrogen is smaller in austenitic (FCC) steels than that in ferritic or martensitic (BCC) steels, the hydrogen diffused distance is shorter in the present TWIP steel. Therefore the tensile test specimens were mechanically polished to a thickness of $0.6 \mathrm{~mm}$ and the surfaces were finally polished by diamond pastes before hydrogen-charging. The present TWIP steel contains aluminum that certain thickness of oxide layer would form at the surface of the specimen, which prevents the permeation of hydrogen into the specimen during hydrogen-charging [17]. Accordingly, the tensile specimens were electrically polished immediately before hydrogen pre-charging in order to remove the surface oxide layers. Hydrogen was then introduced into the tensile test specimens by electrochemical charging in a $3 \% \mathrm{NaCl}$ aqueous solution containing $3 \mathrm{~g} / \mathrm{L}$ of $\mathrm{NH}_{4} \mathrm{SCN}$ at a current density of $100 \mathrm{~A} / \mathrm{m}^{2}$ for $48 \mathrm{~h}$ at room temperature. A platinum plate was used as an anode.

Hydrogen embrittlement behavior was evaluated by a slow strain rate tensile (SSRT) test at room temperature in air. An extensometer was used to measure the strain up to $2 \%$, beyond which the strain was converted from the displacement data recorded during the tensile tests. The tensile tests were carried out at a crosshead speed of $5 \times 10^{-3} \mathrm{~mm} / \mathrm{min}$, corresponding to an initial strain rate of $8.3 \times 10^{-6} \mathrm{~s}^{-1}$. The 
tensile tests were carried out two times for each uncharged and hydrogen-charged specimens to check the reproducibility. After the tensile tests, fracture surfaces of the tensile specimens were examined by FE-SEM.

Diffusible hydrogen content was measured by thermal desorption spectrum (TDS) with gas chromatography at a constant heating rate of $100{ }^{\circ} \mathrm{C} / \mathrm{hr}$ up to the maximum temperature of $800{ }^{\circ} \mathrm{C}$. The gauge part of the tensile specimen was cut immediately after hydrogen-charging. In order to keep the amount of hydrogen that escaped from the specimen surface to the environment the same, all tensile tests and TDS measurements started within $1.8 \mathrm{ks}$ after the completion of hydrogen charging process.

\section{Results}

Figure 1 shows BSE-SEM images of the TWIP steel specimens $92 \%$ cold-rolled and annealed at $650{ }^{\circ} \mathrm{C}$ for $0.3 \mathrm{ks}$ (Figure 1 (a)), $800{ }^{\circ} \mathrm{C}$ for $0.3 \mathrm{ks}$ (Figure 1 (b)) or $1000{ }^{\circ} \mathrm{C}$ for $1.8 \mathrm{ks}$ (Figure 1 (c)). All microstructures show homogeneous and equiaxed grains, which indicates that they are fully recrystallized.

EBSD boundary maps of the cold-rolled and annealed specimens are shown in

Figure 2. Grain boundaries with misorientation between $2^{\circ}$ and $15^{\circ}$ are defined as low-angle grain boundaries, which were indicated as green lines, and those with misorientation larger than $15^{\circ}$ are defined as high-angle grain boundaries, indicated as black lines. $\Sigma 3$ twin boundaries are drawn in red lines. All the specimens have an 
austenite single phase. In addition, large amount of annealing twins were detected in each specimen. The mean grain sizes were measured by using the linear interception method on the EBSD grain boundary maps shown in Figure 2. The grain sizes were measured in two ways: one was measured without annealing twin boundaries and the other one was measured including twin boundaries. The mean grain size of each sample was $0.58 \mu \mathrm{m}, 1.5 \mu \mathrm{m}$ and $19 \mu \mathrm{m}$ including twin boundaries, $0.85 \mu \mathrm{m}, 2.3 \mu \mathrm{m}$ and $37 \mu \mathrm{m}$ without twin boundaries in the $650{ }^{\circ} \mathrm{C}, 800{ }^{\circ} \mathrm{C}$ and $1000{ }^{\circ} \mathrm{C}$-annealed samples, respectively. Hereafter, the specimens are termed as ultrafine-grained, fine-grained and coarse-grained specimens.

Figure 3 shows misorientation distributions corresponding to the microstructures shown in Figure 2. Most of the boundaries in each microstructure are high-angle grain boundaries, which confirm the completion of recrystallization. The fractions of $\Sigma 3$ annealing twin boundaries are $29 \%, 33 \%$, and $41 \%$ in the ultrafine-grained, fine-grained, and coarse-grained specimens, respectively. The fraction of annealing twins decreased with decreasing the grain size.

Figure 4 shows hydrogen desorption rate curves of the various grain sized specimens hydrogen-uncharged (Figure 4 (a)) and hydrogen-charged (Figure 4 (b)). The diffusible hydrogen is reported to play a key role in hydrogen embrittlement [18]. In the present study, diffusible hydrogen content was determined by measuring the accumulated content of desorbed hydrogen from room temperature up to $200{ }^{\circ} \mathrm{C}$. In Figure 4 (a), diffusible hydrogen was not detected in all uncharged specimens with different grain sizes. In contrast, Figure 4 (b) shows large peaks around $110^{\circ} \mathrm{C}$, 
indicating that considerable amount of hydrogen was introduced into the specimens by hydrogen-charging in all different grain-sized specimens. The diffusible hydrogen contents of the hydrogen-charged coarse-grained, fine-grained and ultrafine-grained specimens were $3.30 \mathrm{wt}$ ppm, 4.58 wt ppm, and 7.10 wt ppm, respectively. The amount of diffusible hydrogen content increased significantly with decreasing the grain size. By the way, it is known that solubility of hydrogen in austenitic steel is relatively large but diffusion of hydrogen is slow in austenite. Considering a diffusion coefficient of hydrogen reported in an austenitic steel $(1.29 \times$ $10^{-13} \mathrm{~m}^{2} / \mathrm{s}$ [19]), the diffusion distance of hydrogen is calculated to be around 0.15 mm under the present charging condition (at RT for $48 \mathrm{hr}$ ), which is smaller than the half thickness of the specimens $(0.3 \mathrm{~mm})$. Therefore, there might be an in-depth gradient of hydrogen distribution in the present specimens, but it should be emphasized that the hydrogen charging was carried out under the identical condition to all the specimens.

Nominal stress-strain curves of the hydrogen-uncharged and hydrogen-charged specimens with different grain sizes are shown in Figure 5. The stress-strain curves of the uncharged specimens were indicated by black lines while the hydrogen-charged specimens were indicated by red lines. The grain sizes are also indicated in the figure. The changes of yield strength and ultimate strength are summarized in Figure 6 (a), and the uniform elongation and total elongation are summarized in Figure 6 (b). In the uncharged specimens, the yield strength and tensile strength of the material are greatly enhanced by grain refinement, whereas the total elongation 
decreased with decreasing mean grain size. However, the ultrafine-grained specimen exhibited a large amount of uniform elongation, which is a typical advantage of the TWIP steels [4]. In addition, the uncharged ultrafine-grained specimen exhibits a yield-drop phenomenon, which is often seen in fine-grained materials [20]. Even after hydrogen-charging, the yield strength and the ultimate tensile strength showed no change in each grain sized specimen compared with the uncharged specimen with the same grain size, as indicated in Figure 6 (a). However, hydrogen-charging showed a significant effect on the tensile elongation (Figure 6 (b)). The total elongation greatly decreased from $118 \%$ to $96 \%$ in the coarse-grained specimens by hydrogen-charging. Relatively small decrease of total elongation from $70 \%$ to $63 \%$ was observed in the fine-grained specimen, so that the elongation loss became smaller with decreasing the mean grain size. The uniform elongation and total elongation kept almost the same values in the ultrafine-grained specimens regardless of hydrogen-charging. It means that the mechanical properties become less sensitive to hydrogen with decreasing the grain size. The result also indicates that hydrogen-charging has no influence on the yield strength and tensile strength but a significant impact on the tensile elongation in the Fe-31Mn-3Al-3Si.

Figures 7, 8 and 9 show the fracture surfaces of hydrogen-uncharged and hydrogen-charged specimen with different grain sizes observed by SEM after fracture in the slow strain rate tensile tests. The fracture surfaces were mostly covered with dimples in all specimens regardless of the existence of hydrogen, which are characteristic ductile fracture indicating void nucleation and coalescence. 
Comparing the fracture surfaces of the hydrogen-charged specimens with different grain sizes, it is noteworthy that the coarse-grained specimen exhibited some secondary cracks with length larger than $100 \mu \mathrm{m}$ on the fracture surface (Figure 7 (d)), whereas there are some relatively small cracks in the fine-grained specimen (Figure 8 (d)) and almost no secondary crack was observed in the ultrafine-grained specimen (Figure 9 (d)). In addition, a large number of holes were observed in all the specimens (Figure $7(b, e)$, Figure $8(b, e)$, Figure $9(b, e))$. The holes are probably traces of dropped inclusions that were formed during cold-rolling and annealing process.

Figure 10 shows the true stress-strain curves and work hardening rate curves versus true strain curves corresponding to the nominal stress-strain curves shown in Figure 5. The work hardening rate is sufficiently enhanced in all grain-sized specimens of the 31Mn-3Al-3Si TWIP steel, regardless of hydrogen-charging. The fracture occurred after satisfying the plastic instability condition, at which the strain-hardening rate curve met the flow-stress curve, in all the specimens. However, the work hardening behavior of the hydrogen-charged coarse-grained specimen shows a significant drop at the later stage of plastic deformation, leading to the earlier plastic instability. For the fine-grained specimen, a similar phenomenon is also observed, i.e., slightly earlier plastic instability in the hydrogen-charged specimen than that in the uncharged specimen. On the other hand, in the ultrafine-grained specimen, no significant difference was observed in the work hardening behaviors, indicating that hydrogen-charging did not affect the work hardening behaviors even though the 
amount of diffusible hydrogen was larger in the ultrafine-grained specimen than in grain-sized one (Figure 4).

\section{Discussion}

Possible trapping sites of hydrogen in the present specimens are inclusions, dislocations, twin boundaries, and grain boundaries. For inclusions, the hydrogen trapping energy is reported to be about $79 \mathrm{~kJ} / \mathrm{mol}$ [21]. So et al. [6] reported that the hydrogen trapping energy of twin boundaries was around $62 \mathrm{~kJ} / \mathrm{mol}$. They are considered as trapping sites of non-diffusible hydrogen. Hydrogen trapping energy of dislocations and grain boundaries is in the range of 20-46 kJ / mol [22], so that diffusible hydrogen can be trapped by grain boundaries and dislocations. Since the present specimens have fully recrystallized microstructures, the dislocation densities must be low. Thus, as a first step, we assume that grain boundaries trap all the diffusible hydrogen as an extreme case. The smaller the grain size, the larger the total grain boundary area per unit volume would be. Grain boundary area per unit volume, $S v$, can be expressed as a function of mean interception length of grains (mean grain size), $d$, as:

$$
S v=2 / d
$$

Therefore, the grain boundary area per unit volume in the specimens having the mean grain size without twin boundaries of $37 \mu \mathrm{m}$ (coarse grains), $2.3 \mu \mathrm{m}$ (fine grains) and $0.85 \mu \mathrm{m}$ (ultrafine grains) are $5.4 \times 10^{4} \mathrm{~m}^{2} / \mathrm{m}^{3}, 8.7 \times 10^{5} \mathrm{~m}^{2} / \mathrm{m}^{3}$ and $2.4 \times 10^{6} \mathrm{~m}^{2} / \mathrm{m}^{3}$, 
respectively. Consequently, with decreasing the grain size the trapping sites of hydrogen increases, which coincides with the present result that the largest amount of diffusible hydrogen was introduced in the ultrafine-grained specimen (Figure 4). According to the amount of diffusible hydrogen detected in the present study, however, the corresponding local diffusible hydrogen contents in the unit surface area of grain boundary $\left(x_{H}^{G B}\right)$ are $4.8 \times 10^{-4} \mathrm{~g} / \mathrm{m}^{2}, 4.1 \times 10^{-5} \mathrm{~g} / \mathrm{m}^{2}$ and $2.4 \times 10^{-5} \mathrm{~g} / \mathrm{m}^{2}$, respectively, which are obtained from following formula:

$$
x_{H}^{G B}=w_{H} / S v
$$

where $w_{H}$ is the weight content of hydrogen per unit volume of the specimen. That is, the local hydrogen content at the unit surface area of grain boundary decreased with decreasing the mean grain size, if all hydrogen is trapped at grain boundaries. All these values are summarized in Table 2.

The assumption used in Table 2 that all diffusible hydrogen is trapped at grain boundaries is the most extreme condition and not realistic. A certain amount of hydrogen must exist in the austenite matrix (grain interior) besides at grain boundaries. In fact, it is known that the solubility of hydrogen in austenitic steel is relatively high. According to a previous literature [23], for example, the solubility of hydrogen in Type 304L austenitic stainless steel was 72 wt ppm in $69 \mathrm{MPa}$ hydrogen gas atmosphere at $197{ }^{\circ} \mathrm{C}$. Although it is difficult to experimentally distinguish the amount of hydrogen existing at the grain boundaries from that in the matrix and other trapping sites, we can simply calculate the partition of hydrogen into grain boundaries 
and matrix, by the use of the values shown in Table 2, simply assuming that the total amount of diffusible hydrogen measured by TDS was the sum of the hydrogen in the matrix and the hydrogen trapped at grain boundaries. That is, we have measured the total amount of diffusible hydrogen by TDS, and have calculated the hydrogen content per unit grain boundary area under an assumption that all diffusible hydrogen locates at grain boundaries, for three kinds of specimens with different grain sizes. The relationship between the hydrogen content in the matrix $\left(X_{H}{ }^{M}\right)$ and the hydrogen content per unit grain boundary area $\left(x_{H}{ }^{G B}\right)$ is shown in Figure 11. It was found that three lines intersect to each other at nearly the same point indicated as "A" in the figure, i.e., the coarse-grain's line (black line) meets with those of the fine-grained specimen (red line) and the ultrafine-grained specimens (blue line) at $X_{H}{ }^{M}=3.22 \mathrm{wt}$ ppm and 3.21 wt ppm, respectively, and the line of the fine-grained specimen intersects with that of the ultrafine-grained specimen at $3.10 \mathrm{wt} \mathrm{ppm}$. That is, the figure indicates that the amount of hydrogen at grain boundaries in the fine-grained or ultrafine-grained specimens can be smaller than that in the coarse-grained specimen when $X_{H}{ }^{M}$ is smaller than $3.20 \mathrm{wt}$ ppm. $3.20 \mathrm{wt}$ ppm is $97 \%$ of the total diffusible hydrogen included in the coarse-grained specimen. Even when $X_{H}{ }^{M}$ is larger than $3.20 \mathrm{wt} \mathrm{ppm}$, the amount of hydrogen at grain boundaries in all the specimens are very close. However, this consideration also assumes that the amount of hydrogen in the matrix $\left(X_{H}{ }^{M}\right)$ is the same in all specimens independent of the grain size, which is not guaranteed. Furthermore, it is so far technically difficult to obtain quantitative hydrogen amount at grain boundaries and other trapping sites. At least a 
thermodynamic consideration would be necessary in future for clarifying the partitioning of hydrogen between austenite matrix and grain boundaries.

Besides the static distribution of diffusible hydrogen inside the specimen after hydrogen-charging, it is important to consider hydrogen distribution behavior during deformation (under load). Previous study reported that the diffusible hydrogen atoms tend to accumulate at high stress concentration sites under a load [24]. In addition, Akiyama and Matsuoka [25] confirmed from Ag decoration technique carried out during tensile test that hydrogen accumulated at grain boundaries where some slip lines intercepted in a deformed SUS304 austenitic steel. Plastic deformation gives rise to stress concentration at grain boundaries due to pile-up of dislocations. This suggests that hydrogen in the matrix or trapped at various trapping sites would move and accumulate around grain boundaries during deformation. Because it can be considered that the number of piled-up dislocations at grain boundaries decreases with decreasing the grain size due to smaller space, the stress concentration at grain boundaries in the ultrafine-grained specimen would be much lower than that in the coarse-grained specimen. The lower stress concentration at grain boundaries resulted in the smaller amount of local hydrogen accumulation at grain boundaries in the ultrafine-grained specimen. Accordingly, we infer that the accumulated local hydrogen content at grain boundaries in the ultrafine-grained specimen would be smaller than that in the coarse-grained specimen. Anyhow, these discussions need a confirmation by any evidences in future. 
In the present study, probably because of the higher concentration of local hydrogen, some secondary cracks were observed on the fracture surfaces in the hydrogen-charged specimens with coarser grain sizes (Figure 7 (d), Figure 8 (d)). The formation of secondary cracks caused the decrease of cross-sectional area of the tensile test specimen, then led to the drop in the work hardening rate at the later stage of the tensile test and resulted in the earlier fracture (the earlier plastic instability) compared with the uncharged ones (Figure 10 (a), (b)). The hydrogen-charged coarse-grained specimen had the highest hydrogen accumulation at grain boundaries that the largest amount and longest secondary cracks were observed on the fracture surface (Figure 7 (d)). On the other hand, less secondary cracks were observed in the fine-grained specimen (Figure 8 (d)), and in the ultrafine-grained specimen, probably because the local hydrogen content at grain boundaries was not enough to form cracks.

Accordingly, we conclude that the grain refinement suppressed local accumulation of hydrogen at grain boundaries, resulting in the less sensitivity to the hydrogen embrittlement.

\section{Conclusion}

In the present study, the $31 \mathrm{Mn}-3 \mathrm{Al}-3 \mathrm{Si}$ austenitic TWIP steel having different mean grain sizes of $19 \mu \mathrm{m}, 1.5 \mu \mathrm{m}$, and $0.58 \mu \mathrm{m}$ were fabricated by heavy cold-rolling and subsequent water quenching. The effect of grain size on the 
hydrogen embrittlement behaviors were investigated by slow strain rate tensile tests using hydrogen pre-charged specimens. Hydrogen-charging had no influence on the yield strength and tensile strength but induced a significant decrease in the tensile elongation with increasing the mean grain size. The diffusible hydrogen content increased with decreasing the mean grain size. Partitioning of hydrogen at grain boundaries both under static condition just after hydrogen-charging and during tensile test was qualitatively discussed. Possibilities of lower concentration of hydrogen in the finer grain-sized specimen, that can be a reason for the formation of secondary cracks and degradation of mechanical properties in the hydrogen-charged coarse-grained specimen, were suggested, but quantitative confirmation of hydrogen accumulation at grain boundaries would be necessary in future. It could be concluded from the experimental results obtained in the present study that grain refinement could suppress hydrogen embrittlement in the 31Mn-3Al-3Si TWIP steel. 


\section{Acknowledgement}

The present study was financially supported by the Elements Strategy Initiative for Structural Materials (ESISM), and by the Grant-in-Aid for Scientific Research on

Innovative Area "Bulk Nanostructured Metals" (area No.2201), both through the Ministry of Education, Culture, Sports, Science and Technology (MEXT), Japan. Yu Bai was supported by the Japanese Government Scholarship. All these supports are gratefully appreciated by the authors. 


\section{References}

[1] O. Grässel, G. Frommeyer, Mater. Sci. Technol. 14 (1998) 1213-1217.

[2] K. Sato, M. Ichinose, Y. Hirotsu, Y. Inoue, ISIJ Int. 29 (1989) 868-877.

[3] L. Chen, S.J. Lee, B.C.D. Cooman, ISIJ Int. 52 (2012) 1670-1677.

[4] R. Ueji, N. Tsuchida, D. Terada, N. Tsuji, Y. Tanaka, A. Takemura, K. Kunishige, Scr. Mater. 59 (2008) 963-966.

[5] J.A. Ronevich, J.G. Speer, D.K. Matlock, SAE Int. J. Mater. Manuf. 3 (2010) $255-267$.

[6] K.H. So, J.S. Kim, Y.S. Chun, K.T. Park, Y.G. Lee, C.S. Lee, ISIJ Int. 49 (2009) 1952-1959.

[7] J.K. Jung, O.Y. Lee, Y.K. Park, D.E. Kim, K.G. Jin, Korean J. Mater. Res. 18 (2008) 394-399.

[8] S.C. Mittal, R.C. Prasad, M.B. Deshmuk, ISIJ Int. 34 (1994) 211-216.

[9] M. Koyama, E. Akiyama, K. Tsuzaki, Corros. Sci. 54 (2012) 1-4.

[10] M. Koyama, E. Akiyama, K. Tsuzaki, Corros. Sci. 59 (2012) 277-281.

[11] I.J. Park, J.G. Jung, S.Y. Jo, S.M. Lee, Y.K. Lee, Mater. Trans. 55 (2014) 964-970.

[12] J.S. Kim, Y.H. Lee, D.L. Lee, K.T. Park, C.S. Lee, Mater. Sci. Eng. A 505 (2009) 105-110.

[13] W.D. Callister, D.G. Rethwisch, Materials Science and Engineering, eighth ed., Wiley, 2011. 
[14] R. Saha, R. Uejib, N. Tsuji, Scr. Mater. 68 (2013) 813-816.

[15] J. Yamamoto, R \& D Kobe steel engineering report, 18 (1968) 93.

[16] S.A. Akbari, J. Imlau, U. Prahl, W. Bleck, Metall. Mater. Trans. A 40 (2009) 3076-3090.

[17] I.J. Park, K.H. Jeong, J.G. Jung, C.S. Lee and Y.K. Lee, Int. J. Hydrogen Energy, 37 (2012) 9925-9932.

[18] K. Takai, R. Watanuki, ISIJ Int. 43 (2003) 520-526.

[19] S.K. Kim, P.Y. Oh, S.H. Jeon, S.H. Han, S.E. Kang, K.G. Chin, Gent, Steely Hydrogen Conference Proceedings, (2011) 189.

[20] S. Gao, M.C. Chen, S. Chen, N. Kamikawa, A. Shibata1, N. Tsuji, Mater. Trans. 55 (2014) 73-77.

[21] C.S. Lee, Proc. of the Workshop on High Mn Steels, GIFT, Pohang, South Korea, 2009.

[22] J.P. Hirth, Metall. Trans. A 11A (1980) 861.

[23] G.R. Caskey, R.D. Sisson, Scr. Mater. 15 (1981) 1187-1190.

[24] R.A. Oriani, J.P. Hirth, M. Smialowski, Hydrogen Degradation of Ferrous Alloys, Noyes Publications, 1985.

[25] E. Akiyama, S. Matsuoka, Mater. Trans. 56 (2015) 793-797. 


\section{Figure and Table Captions}

Table 1 Chemical composition of the Fe-Mn-Al-Si TWIP steel used in the present study (mass \%).

Figure 1 BSE-SEM images of the Fe-31Mn-3Al-3Si specimens after cold-rolling and annealing at various temperatures for different periods: (a) at $650{ }^{\circ} \mathrm{C}$ for $0.3 \mathrm{ks}$, (b) at $800{ }^{\circ} \mathrm{C}$ for $0.3 \mathrm{ks}$, and (c) at $1000{ }^{\circ} \mathrm{C}$ for $1.8 \mathrm{ks}$, respectively. Observed from TD.

Figure 2 EBSD grain boundaries maps of the Fe-31Mn-3Al-3Si specimens after $92 \%$ cold-rolling and annealing at various temperatures for different periods: (a) at $650{ }^{\circ} \mathrm{C}$ for $0.3 \mathrm{ks}$, (b) at $800{ }^{\circ} \mathrm{C}$ for $0.3 \mathrm{ks}$, and (c) at $1000{ }^{\circ} \mathrm{C}$ for $1.8 \mathrm{ks}$, respectively. Observed from TD. The green, black and red lines correspond to low-angle boundaries, high-angle boundaries and $\Sigma 3$ twin boundaries, respectively. The high-angle boundaries were determined as boundaries with misorientation larger than $15^{\circ}$, and low-angle boundaries with misorientation between $2^{\circ}$ and $15^{\circ}$, respectively.

Figure 3 Misorientation distributions of the specimens cold-rolled and annealed (a) at $650{ }^{\circ} \mathrm{C}$ for $0.3 \mathrm{ks}$, (b) at $800{ }^{\circ} \mathrm{C}$ for $0.3 \mathrm{ks}$, (c) at $1000{ }^{\circ} \mathrm{C}$ for $1.8 \mathrm{ks}$, corresponding to Figure 2.

Figure 4 Hydrogen desorption rate curves of the differently grain-sized specimens hydrogen-uncharged (a) and hydrogen-charged (b). 
Figure 5 Nominal stress-strain curves of the differently grain-sized specimens with and without hydrogen-charging.

Figure 6 Comparison of the tensile properties of the hydrogen-uncharged and hydrogen-charged TWIP steel, as a function of mean grain size. (a) The yield strength $\left(s_{\mathrm{y}}\right)$ and ultimate tensile strength $\left(s_{\mathrm{UTS}}\right)$; $(\mathrm{b})$ the uniform elongation $\left(e_{\text {uniform }}\right)$ and total elongation $\left(e_{\text {total }}\right)$.

Figure 7 Fracture surfaces of the coarse-grained specimens hydrogen-uncharged (a-c) and hydrogen-charged (d-f). (a) is the entire fracture surface of the hydrogen-uncharged specimen, (b) and (c) are the magnified images of (a). (d) is the entire fracture surface of the hydrogen-charged specimen, (e) and (f) are the magnified images of (d).

Figure 8 Fracture surfaces of the fine-grained specimens with hydrogen-uncharged (a-c) and hydrogen-charged (d-f). (a) is the entire fracture surface of the hydrogen-uncharged specimen, (b) and (c) are the magnified images of (a). (d) is the entire fracture surface of the hydrogen-charged specimen, (e) and (f) are the magnified images of (d).

Figure 9 Fracture surfaces of the ultrafine-grained specimens with hydrogen-uncharged (a-c) and hydrogen-charged (d-f). (a) is the entire fracture 
surface of the hydrogen-uncharged specimen, (b) and (c) are the magnified images of (a). (d) is the entire fracture surface of the hydrogen-charged specimen, (e) and (f) are the magnified images of (d).

Figure 10 True stress-strain curves and work hardening rate versus true strain curves of the differently grain-sized specimens with and without hydrogen-charging: (a) coarse-grained specimens, (b) fine-grained specimens, and (c) ultrafine-grained specimens.

Table 2 Summary of the grain size $(d)$, grain boundary area per unit volume $(S v)$, content of diffusible hydrogen $\left(X_{H}^{\text {all }}\right)$, and hydrogen content per unit grain boundary area $\left(x_{H}^{G B}\right)$ calculated under an assumption that all hydrogen locates at grain boundaries.

Figure 11 Relationship between the hydrogen content in austenite matrix (grain interior) and the hydrogen content per unit grain boundary area, which is obtained from the values in Table 2. The point A around which the hydrogen content per unit grain boundary area of the coarse-grained specimens becomes smaller than that of the fine-grained and ultrafine-grained specimens corresponds to around $3.2 \mathrm{wt}$ ppm of the hydrogen content in the matrix. 

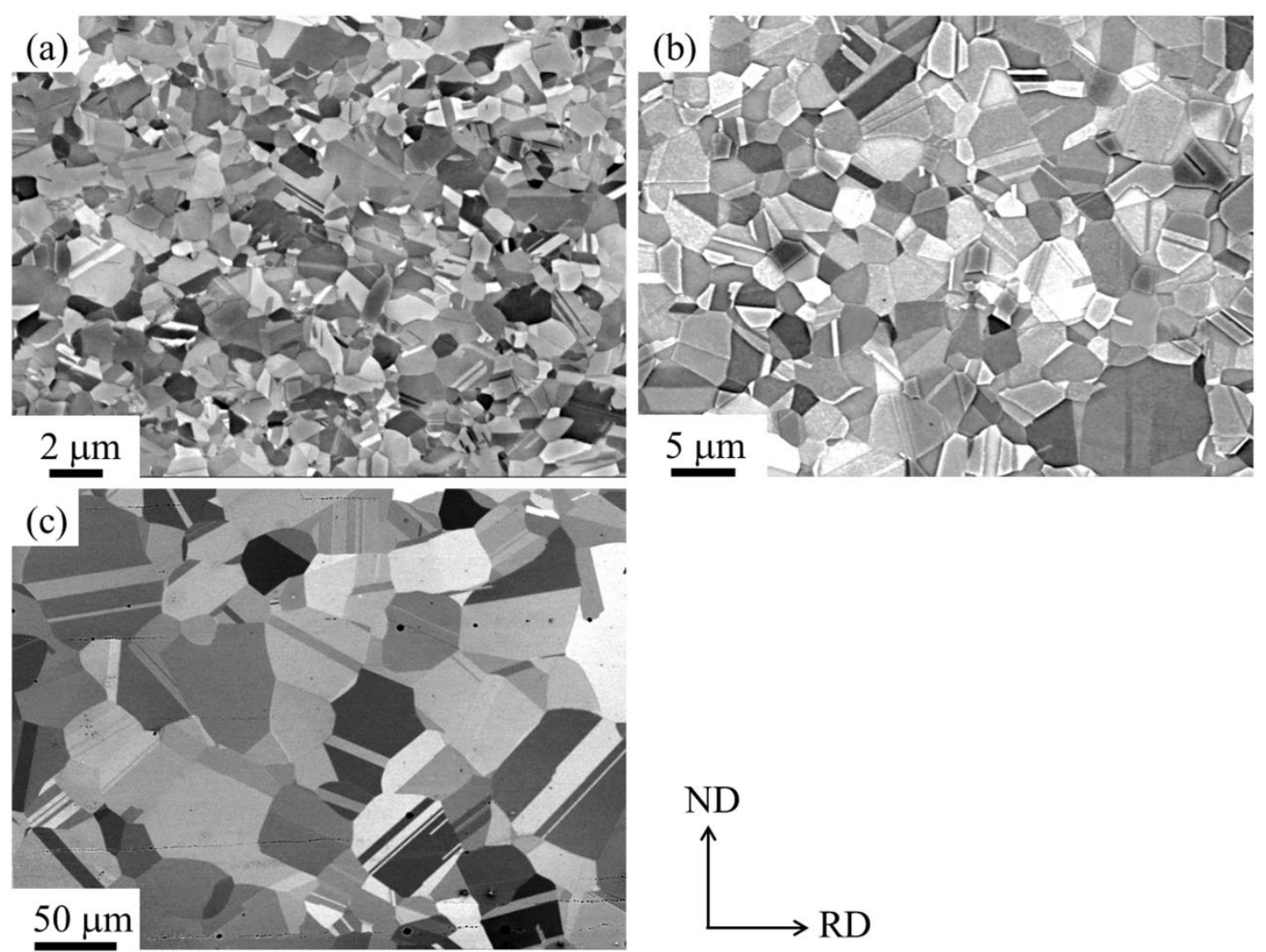

Figure 1 BSE-SEM images of the Fe-31Mn-3Al-3Si specimens after cold-rolling and annealing at various temperatures for different periods: (a) at $650{ }^{\circ} \mathrm{C}$ for $0.3 \mathrm{ks}$, (b) at $800^{\circ} \mathrm{C}$ for $0.3 \mathrm{ks}$, and (c) at $1000^{\circ} \mathrm{C}$ for $1.8 \mathrm{ks}$, respectively. Observed from TD. 

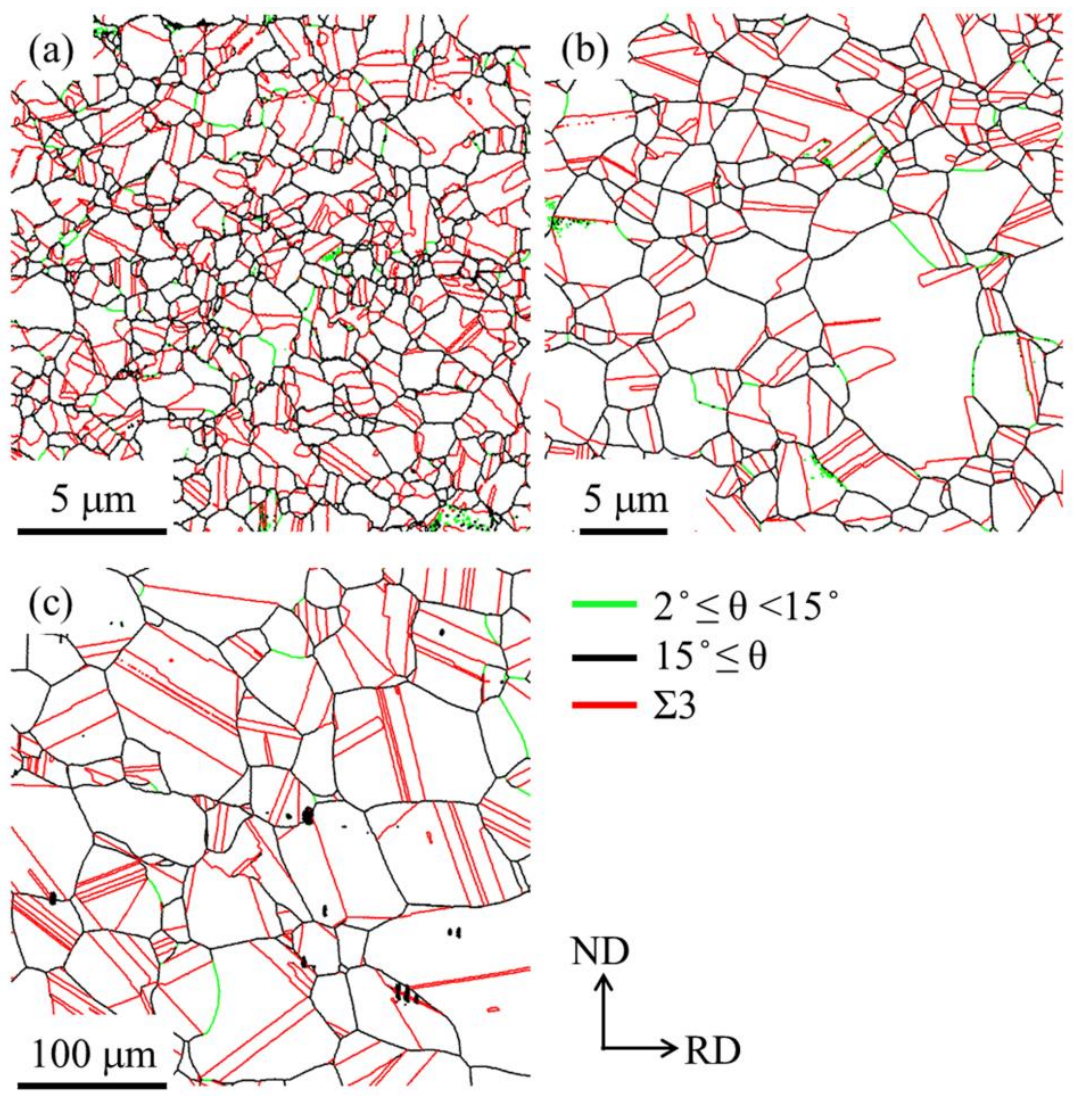

Figure 2 EBSD grain boundaries maps of the Fe-31Mn-3Al-3Si specimens after $92 \%$ cold-rolling and annealing at various temperatures for different periods: (a) at $650{ }^{\circ} \mathrm{C}$ for $0.3 \mathrm{ks}$, (b) at $800{ }^{\circ} \mathrm{C}$ for $0.3 \mathrm{ks}$, and (c) at $1000{ }^{\circ} \mathrm{C}$ for $1.8 \mathrm{ks}$, respectively. Observed from TD. The green, black and red lines correspond to low-angle boundaries, high-angle boundaries and $\Sigma 3$ twin boundaries, respectively. The highangle boundaries were determined as boundaries with misorientation larger than $15^{\circ}$, and low-angle boundaries with misorientation between $2^{\circ}$ and $15^{\circ}$, respectively. 

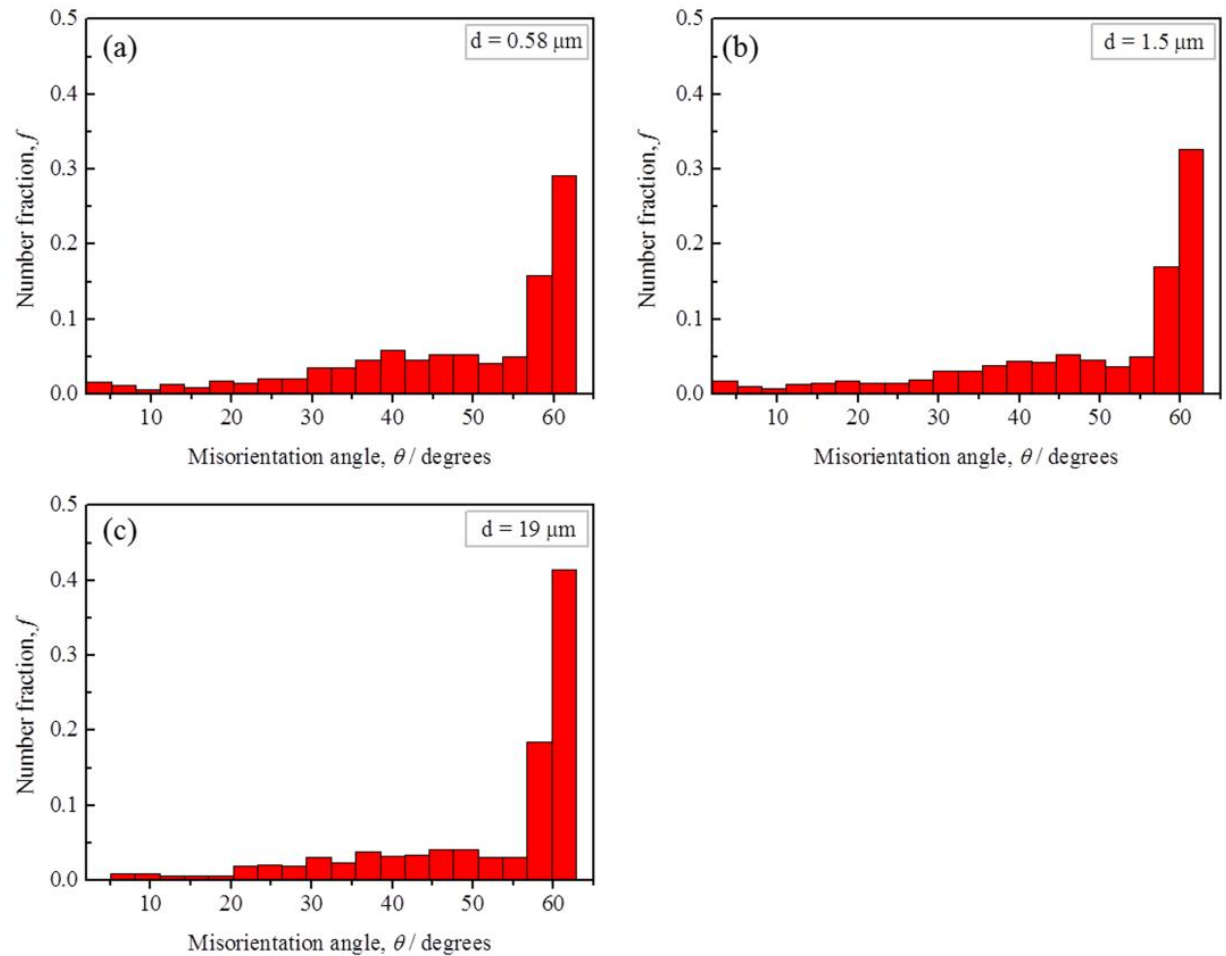

Figure 3 Misorientation distributions of the specimens cold-rolled and annealed (a) at $650{ }^{\circ} \mathrm{C}$ for $0.3 \mathrm{ks},(\mathrm{b})$ at $800^{\circ} \mathrm{C}$ for $0.3 \mathrm{ks}$, (c) at $1000^{\circ} \mathrm{C}$ for $1.8 \mathrm{ks}$, corresponding to Figure 2. 

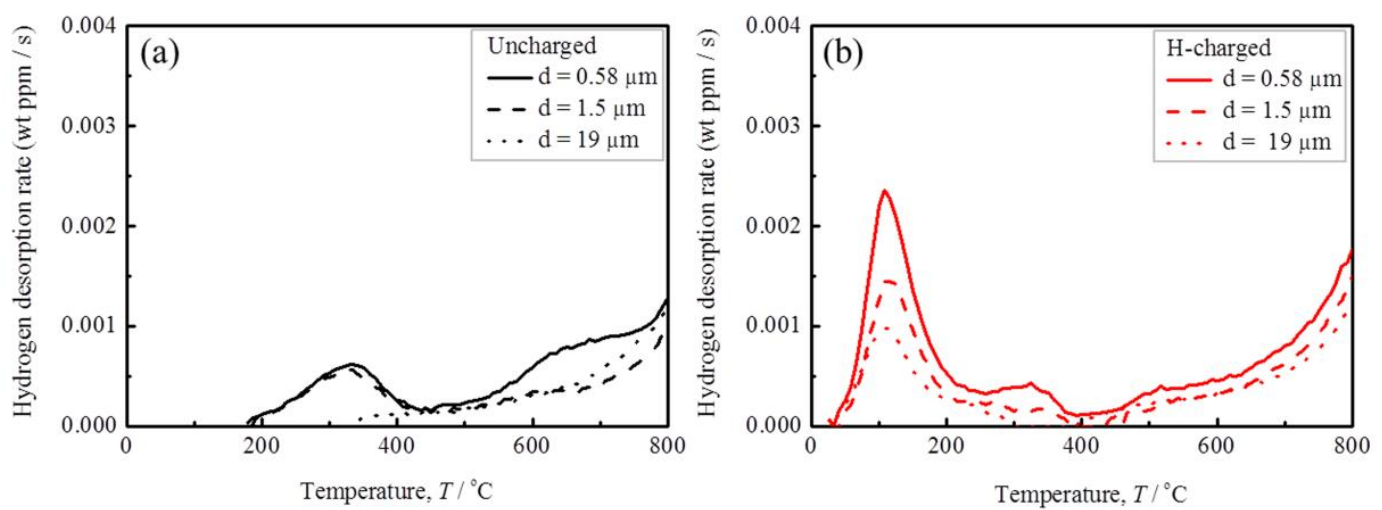

Figure 4 Hydrogen desorption rate curves of the differently grain-sized specimens hydrogen-uncharged (a) and hydrogen-charged (b). 


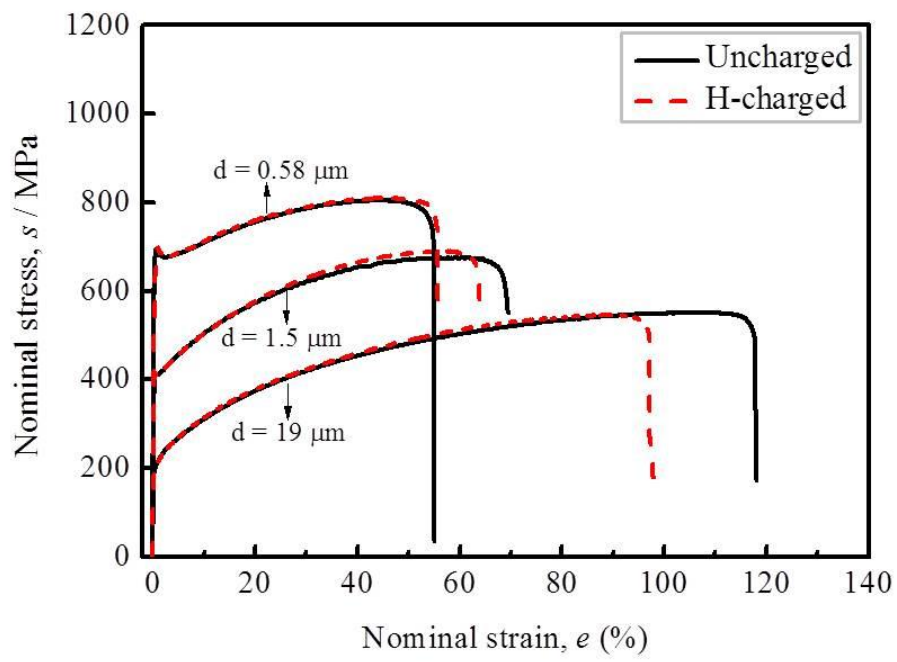

Figure 5 Nominal stress-strain curves of the differently grain-sized specimens with and without hydrogen-charging. 

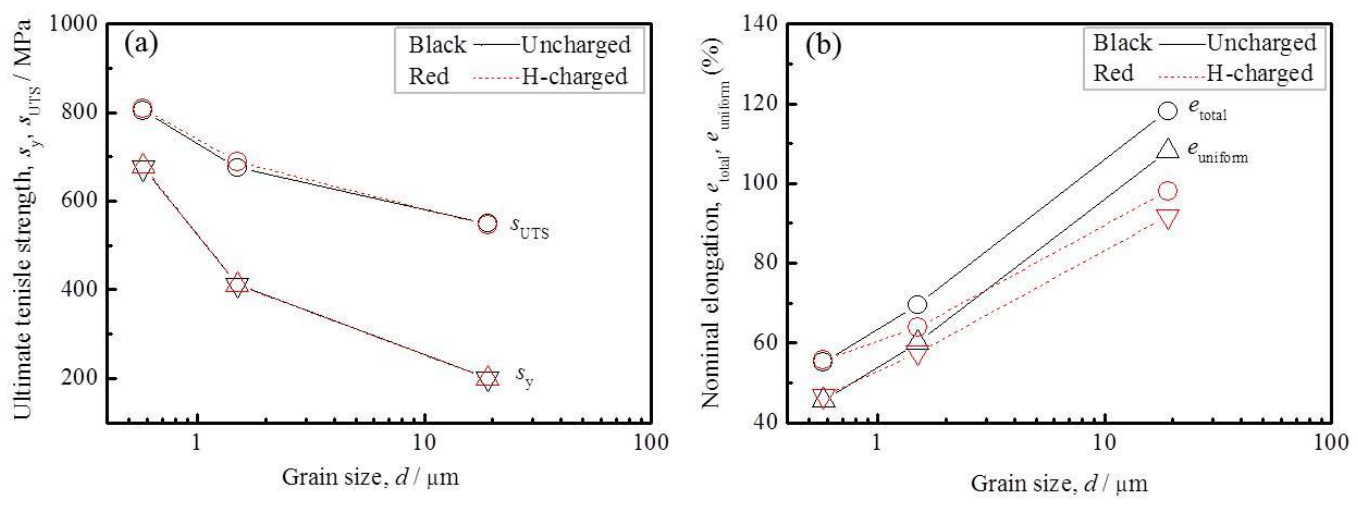

Figure 6 Comparison of the tensile properties of the hydrogen-uncharged and hydrogen-charged TWIP steel, as a function of mean grain size. (a) The yield strength $\left(s_{\mathrm{y}}\right)$ and ultimate tensile strength $\left(s_{\mathrm{UTS}}\right)$; (b) the uniform elongation $\left(e_{\text {uniform }}\right)$ and total elongation $\left(e_{\text {total }}\right)$ 

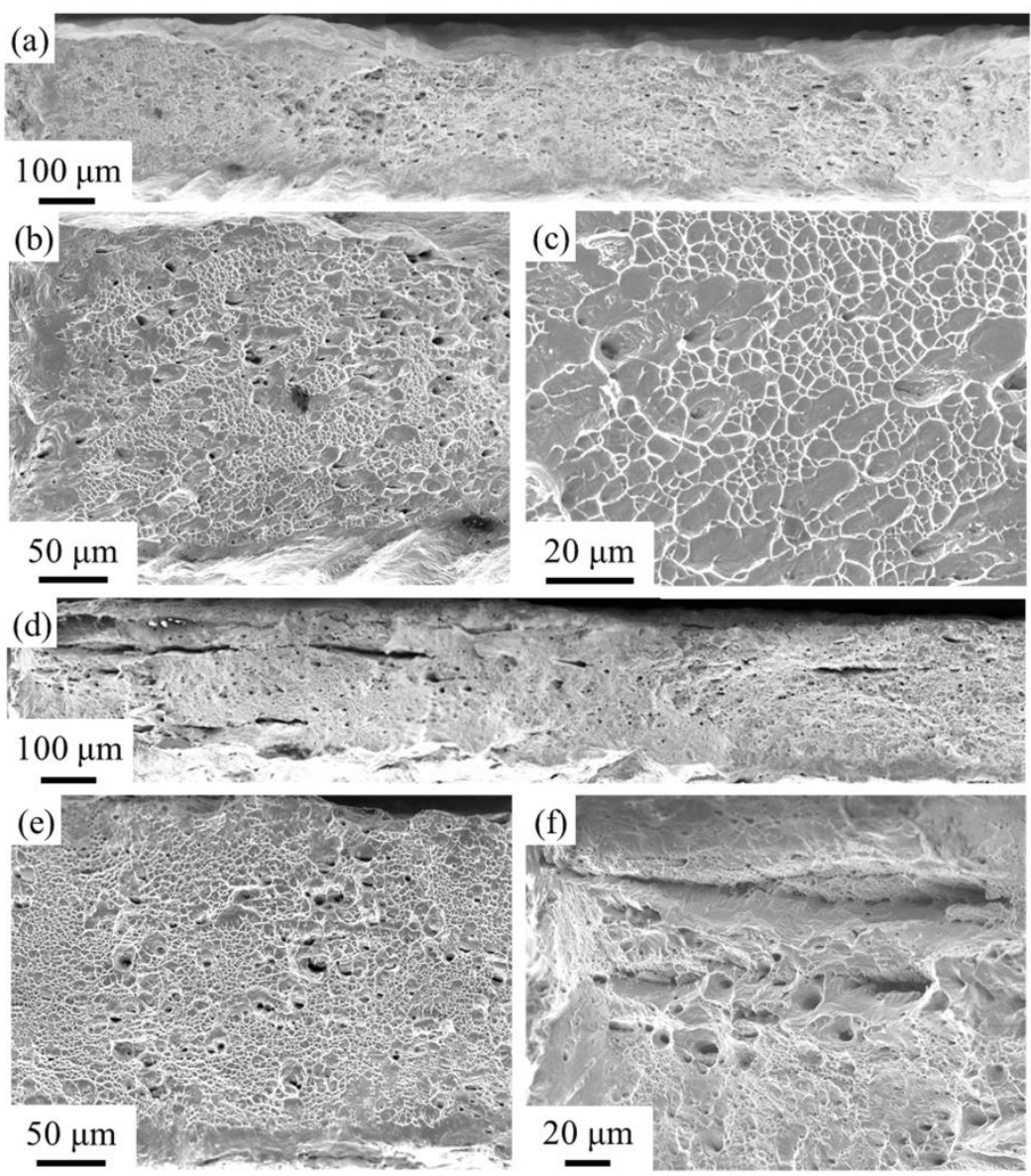

Figure 7 Fracture surfaces of the coarse-grained specimens hydrogen-uncharged (a-c) and hydrogen-charged (d-f). (a) is the entire fracture surface of the hydrogen-uncharged specimen, (b) and (c) are the magnified images of (a). (d) is the entire fracture surface of the hydrogen-charged specimen, (e) and (f) are the magnified images of (d). 

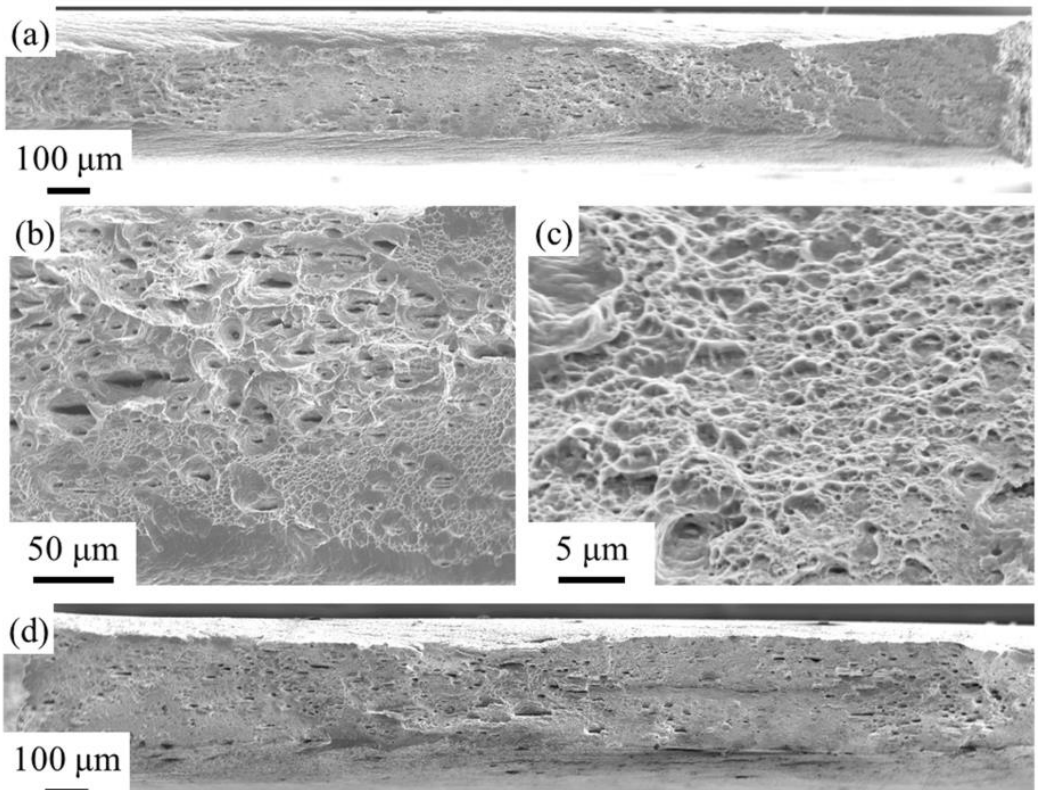

(e)
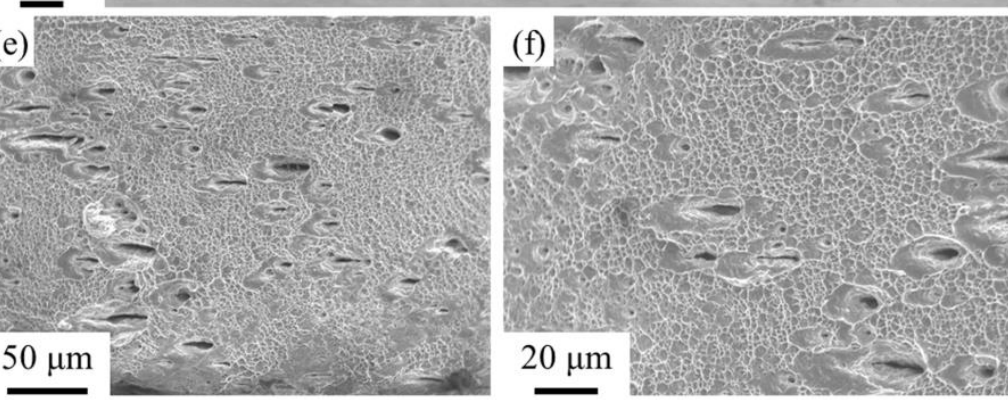

Figure 8 Fracture surfaces of the fine-grained specimens with hydrogen-uncharged (a-c) and hydrogen-charged (d-f). (a) is the entire fracture surface of the hydrogen-uncharged specimen, (b) and (c) are the magnified images of (a). (d) is the entire fracture surface of the hydrogen-charged specimen, (e) and (f) are the magnified images of (d). 

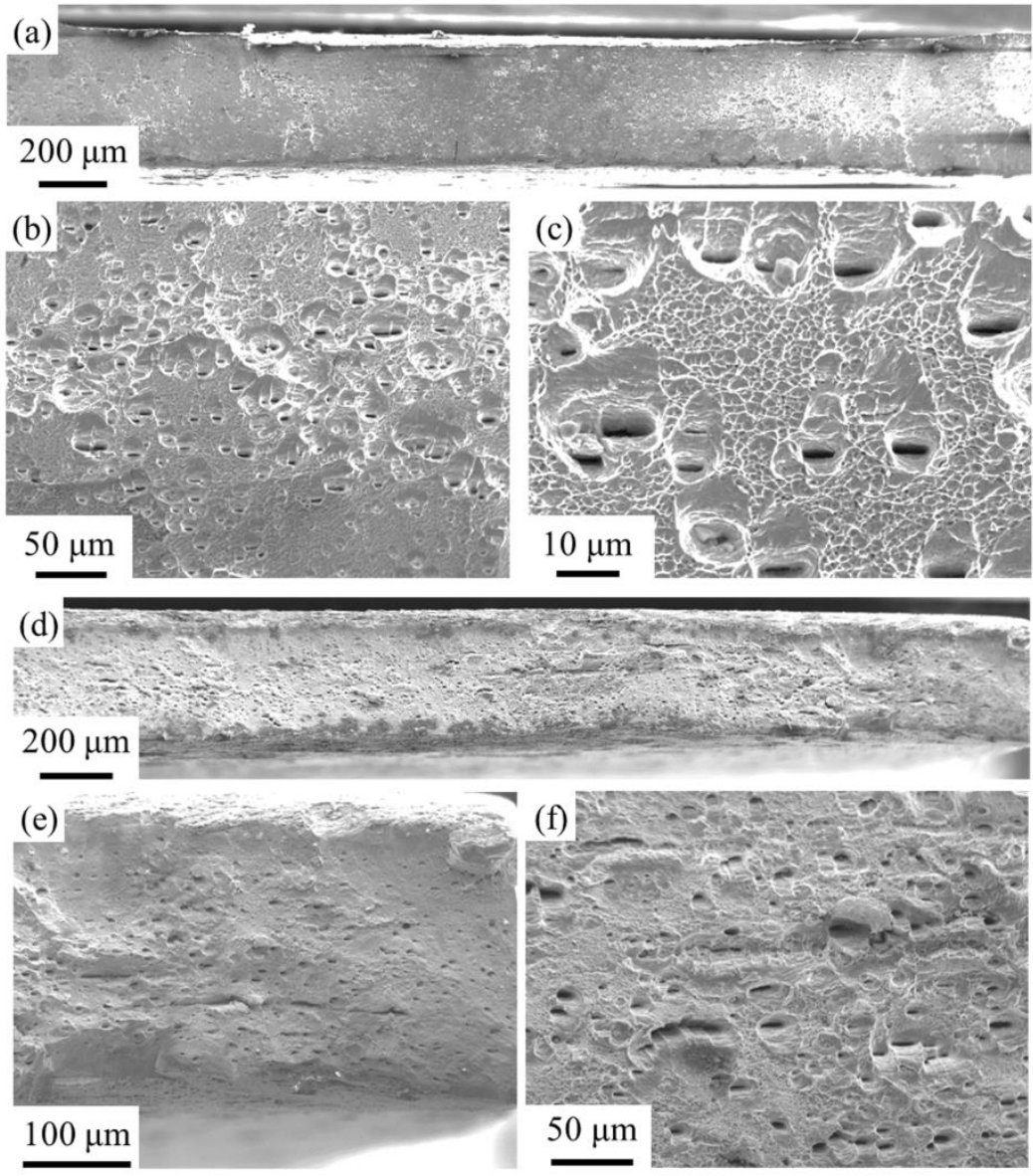

Figure 9 Fracture surfaces of the ultrafine-grained specimens with hydrogen-uncharged (a-c) and hydrogen-charged (d-f). (a) is the entire fracture surface of the hydrogenuncharged specimen, (b) and (c) are the magnified images of (a). (d) is the entire fracture surface of the hydrogen-charged specimen, (e) and (f) are the magnified images of (d). 

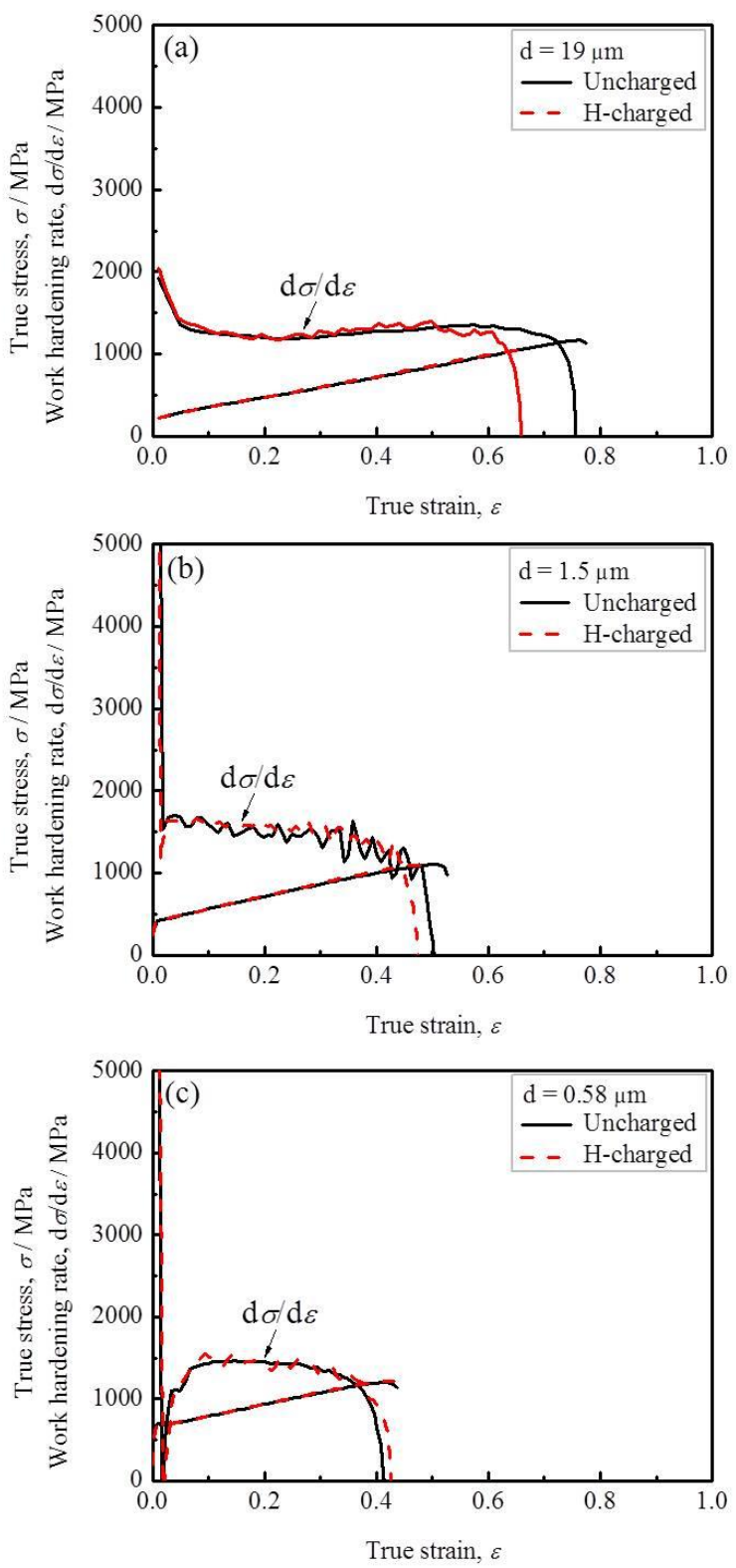

Figure 10 True stress-strain curves and work hardening rate versus true strain curves of the differently grain-sized specimens with and without hydrogen-charging: (a) coarse-grained specimens, (b) fine-grained specimens, and (c) ultrafine-grained specimens. 


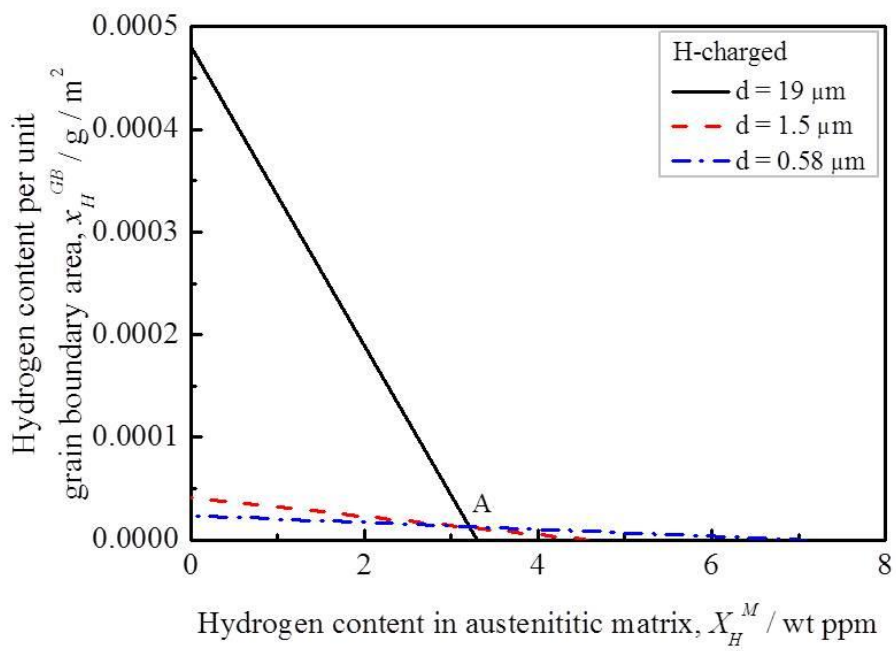

Figure 11 Relationship between the hydrogen content in austenite matrix (grain interior) and the hydrogen content per unit grain boundary area, which is obtained from the values in Table 2. The point A around which the hydrogen content per unit grain boundary area of coarse-grained specimens becomes smaller than that of the fine-grained and ultrafine-grained specimens corresponds to around $3.2 \mathrm{wt}$ ppm of the hydrogen content in the matrix. 
Table 1 Chemical composition of the Fe-Mn-Al-Si TWIP steel used in the present study (mass \%).

\begin{tabular}{ccccccc}
\hline $\mathrm{Mn}$ & $\mathrm{Si}$ & $\mathrm{Al}$ & $\mathrm{C}$ & $\mathrm{N}$ & $\mathrm{S}$ & $\mathrm{Fe}$ \\
\hline 31 & 3.0 & 3.0 & 0.005 & 0.004 & 0.012 & Bal. \\
\hline
\end{tabular}


Table 2 Summary of the grain size $(d)$, grain boundary area per unit volume $(S v)$, content of diffusible hydrogen $\left(X_{H}{ }^{a l l}\right)$, and hydrogen content per unit grain boundary area $\left(x_{H}^{G B}\right)$ calculated under an assumption that all hydrogen locates at grain boundaries.

\begin{tabular}{cccc}
\hline $\begin{array}{c}\text { Grain size, } d \\
(\mu \mathrm{m})\end{array}$ & $\begin{array}{c}\text { Grain boundary area } \\
\text { per unit volume, } S v \\
\left(\mathrm{~m}^{2} / \mathrm{m}^{3}\right)\end{array}$ & $\begin{array}{c}\text { Content of diffusible } \\
\text { hydrogen, } X_{H} \text { all } \\
(\mathrm{wt} \mathrm{ppm})\end{array}$ & $\begin{array}{c}\text { Hydrogen content } \\
\text { per unit grain } \\
\text { boundary area, } x_{H}{ }^{G B} \\
\left(\mathrm{~g} / \mathrm{m}^{2}\right)\end{array}$ \\
\hline 37 & $5.4 \times 10^{4}$ & 3.30 & $4.8 \times 10^{-4}$ \\
\hline 2.3 & $8.7 \times 10^{5}$ & 4.58 & $4.1 \times 10^{-5}$ \\
\hline 0.85 & $2.4 \times 10^{6}$ & 7.10 & $2.4 \times 10^{-5}$ \\
\hline
\end{tabular}

